Pacific Journal of Mathematics

SEMIFREE FINITE GROUP ACTIONS ON HOMOTOPY
SPHERES 


\title{
SEMIFREE FINITE GROUP ACTIONS ON HOMOTOPY SPHERES
}

\author{
RONALD M. DOTZEL
}

\begin{abstract}
Suppose $G$ is a finite group acting semifreely (i.e., free off the fixed set) on a finite $C W$ complex $X$ in the homotopy type of $S^{n}$. When $X^{a}$ is also homotopy equivalent to $S^{n}$ (as e.g., in $S^{n} \times D^{K}$ ) necessary and sufficent conditions are given to determine the degree of the inclusion $X^{G} \rightarrow X$. It follows that for instance, if $G$ is the group of quaternions (nonabelian of order 8), the only attainable degrees are those $\pm 1(\bmod 8)$.
\end{abstract}

o. Introduction. Suppose that $G$ is a finite group acting cellularly and semifreely (i.e., free off the fixed set) on a finite $C W$ complex $X$, in the homotopy type of $S^{n}$. Assume that $X^{G}$ is also homotopy equivalent to $S^{n}$. The degree $q$ of the inclusion $X^{G} \hookrightarrow X$ is defined and by Smith Theory is relatively prime to $|G|$ (see [1; Chap. III]). We give necessary and sufficient conditions for the converse to be true. First recall that when $q$ is relatively prime to $|G|$, the trivial $\boldsymbol{Z} G$-module $\boldsymbol{Z}_{q}$ has projective dimension one and well-defines an element, $\left[\boldsymbol{Z}_{q}\right]$, in $\widetilde{K}_{0}(\boldsymbol{Z} G)$, the reduced projective class group.

THEOREM. Let $G$ be a finite group acting cellularly and semifreely on a finite $C W$ complex $X$. Assume that both $X$ and $X^{G}$ are in the homotopy type of $S^{n}$. Let $q$ be the degree of $X^{G} \hookrightarrow X$. Then $\left[\boldsymbol{Z}_{q}\right]=0$ in $\widetilde{K}_{0}(\boldsymbol{Z} G)$. Conversely, suppose $q$ is relatively prime to $|G|$ and $\left[\boldsymbol{Z}_{q}\right]=0$ in $\widetilde{K}_{0}(\boldsymbol{Z} G)$. Then there exists an action of $G$, as above, in which the degree of $X^{G} \hookrightarrow X$ is $q$.

REMARKS. (i ) From [2] it follows, e.g., that the quaternions, a nonabelian group of order 8 , cannot act semifreely as above with degree of the inclusion $\pm 3(\bmod 8)$.

(ii) When $G$ is cyclic and $q$ is prime to $|G|,\left[Z_{q}\right]$ is always zero $[4 ; \S 6]$ and therefore it is easy to see how to construct an effective, unrestricted action of the quaternions realizing a degree 3 inclusion. In [1; page 391], Bredon gave examples of semifree (smooth) cyclic group actions realizing any (appropriate) degree. In general, of course, one cannot hope to find smooth semifree actions of this type.

(iii) The invariant introduced here is in fact the same as the invariant, $\chi(f)$, introduced in [3] (when applied to the inclusion map). 
1. Proof of the theorem. Suppose $G$ is a finite group acting as described and let $q$ denote the degree of $X^{G} \rightarrow X . \quad X / X^{G}$ has semifree $G$ action with one fixed point, is $n-1$ connected and has $H_{n}\left(X / X^{G}\right)=\boldsymbol{Z}_{q}$. By an elementary construction (a nonequivariant version can be found in [5; Prop. 6.13]) one can replace $X / X^{G}$ with a finite $C W$-complex $Y$, with semifree $G$-action, contractible fixed set, no $m$ cells for $0<m \leqq n-1$ and such that $X / X^{G}$ is an equivariant strong deformation retract of $Y$. Let $k$ denote the cellular dimension of $Y$. Then

$$
0 \longrightarrow C_{k}\left(Y, Y^{G}\right) \longrightarrow \cdots \longrightarrow C_{n+1}\left(Y, Y^{G}\right) \longrightarrow C_{n}\left(Y, Y^{G}\right) \longrightarrow Z_{q}
$$

is a finite free resolution of $\boldsymbol{Z}_{q}$ over $\boldsymbol{Z} G$. This implies that $\left[\boldsymbol{Z}_{q}\right]=0$ in $\widetilde{K}_{0}(\boldsymbol{Z} G)$.

Now suppose $q$ is relatively prime to $|G|$ and that $\left[Z_{q}\right]=0$ in $\widetilde{K}_{0}(Z G)$. Let $M_{f}$ be the mapping cylinder of a map $f: S^{n} \rightarrow S^{n}$ of degree $q ; M_{f}=S^{n} \times I \cup S^{n} /(x, 0) \sim f(x)$. Denote by $Y$ the semifree $G$-complex obtained by taking the disjoint union of $|G|$ copies of $M_{f}$, identified along the sphere $S^{n} \times\{1\}$. G acts on $Y$ via the action induced from the free action on the disjoint union; the fixed set is $S^{n}$.

It follows from Mayer-Vietoris that if $I_{\varepsilon}$ denotes the augmentation ideal, i.e., the kernel of $\boldsymbol{Z} G \stackrel{\varepsilon}{\rightarrow} \boldsymbol{Z}$ (where $\left.\varepsilon\left(\Sigma n_{i} g_{i}\right)=\Sigma n_{i}\right)$, then $H_{n}(Y)=Z G / q I_{\varepsilon}$.

There is the exact sequence of $\boldsymbol{Z} G$-modules,

$$
0 \longrightarrow I_{\varepsilon} / q I_{\varepsilon} \longrightarrow H_{n}(Y) \longrightarrow Z \text {. }
$$

Since $I_{\varepsilon} / q I_{\varepsilon}$ has projective dimension one, it well-defines an element $\left[I_{\varepsilon} / q I_{\varepsilon}\right]$ in $\widetilde{K}_{0}(Z G)$.

Now consider the exact sequence of $\boldsymbol{Z} G$-modules $\left(\boldsymbol{Z}_{q}\right.$ has trivial G-action),

$$
\mathbf{0} \longrightarrow \operatorname{ker} \varepsilon_{q} \longrightarrow Z G \stackrel{\varepsilon_{q}}{\longrightarrow} \boldsymbol{Z}_{q}
$$

where $\varepsilon_{q}$ is $\varepsilon$ followed by reduction $\bmod q$ ). Since $\boldsymbol{Z}_{q}$ has projective dimension one, it well-defines an element in $\widetilde{K}_{0}(\boldsymbol{Z} G)$ which is $-\left[\operatorname{ker} \varepsilon_{q}\right]$. $\operatorname{Ker} \varepsilon_{q}$ and $I_{\varepsilon} / q I_{\varepsilon}$ are related by the exact sequence

$$
0 \longrightarrow Z G \stackrel{q}{\longrightarrow} \operatorname{ker} \varepsilon_{q} \longrightarrow I_{\varepsilon} / q I_{\varepsilon} \text {. }
$$

The assumption that $\left[Z_{q}\right]=0$ forces $\left[I_{\varepsilon} / q I_{\varepsilon}\right]=0$ and so $I_{\varepsilon} / q I_{\varepsilon}$ has a short exact projective resolution

$$
0 \longrightarrow \widetilde{F} \longrightarrow F_{0} \longrightarrow I_{\varepsilon} / q I_{\varepsilon}
$$

where $F_{0}$ is free and $\widetilde{F}$ is stably free. Adding free orbits of $n+1$ 
cells to $Y$ to kill $I_{\varepsilon} / q I_{\varepsilon}$ (realizing $F_{0} \rightarrow I_{\varepsilon} / q I_{\varepsilon}$ ) produces $\tilde{Y}$ with $H_{n+1}(\tilde{Y})=\widetilde{F}, H_{n}(\tilde{Y})=Z$. Using the surjective Hurewicz homomorphism ( $\tilde{Y}$ is $n-1$ connected), $n+2$ cells may be added $\left(H_{n+1}(\tilde{Y})\right.$ is made free by wedging, at a fixed point, with a suitable bouquet of spheres) to produce the complex $X$ which is homotopy equivalent to $S^{n}$. By considering the homology sequence of the triple $\left(X, \tilde{Y}, Y^{G}\right)$ one can see that the degree $X^{G} \hookrightarrow X$ is $q$.

As in $[4 ; \S 6]$, let $(q, N)$ denote the ideal of $Z G$ generated by $q$ (relatively prime to $|G|$ ) and $N=\sum_{g \in G} g$. It is easy to see that $\left[\boldsymbol{Z}_{q}\right]=[(q, N)]$ in $\widetilde{K}_{0}(\boldsymbol{Z} G)$. This explains Remark (i).

\section{REFERENCES}

1. G. Bredon, Introduction to Compact Transformation Groups, Academic Press, 1972.

2. J. Martinet, Modules Sur L'Algèbre Du Groupe Quaternionen, Ann. Scient. Ec. Norm. Sup., $4^{\circ}$ serie, t. 4, 1971, p. 309 à 408.

3. T. Petrie, $G$ maps and the projective class group, Comment. Math. Helvertici, 39 (51), 611-626.

4. R. Swan, Periodic resolutions for finite groups, Annals of Math., 72 (1960), 267-291.

5. R. Switzer, Algebraic Topology-Homotopy and Homology, Springer-Verlag, 1975.

Received September 26, 1980.

The UNIVERSITY OF TeXaS

AUstin, TX 78712

Current Address:

Department of Mathematics

UNIVERSITY OF MISSOURI-ST. LOUIS

St. LouIs, Missouri 63121 



\section{PACIFIC JOURNAL OF MATHEMATICS}

\section{EDITORS}

DONALD BABBITT (Managing Editor)

University of California

Los Angeles, California 90024

Hugo RossI

University of Utah

Salt Lake City, UT 84112

C. C. Moore and Arthur Agus

University of California

Berkeley, CA 94720
J. DugundJI

Department of Mathematics University of Southern California Los Angeles, California 90007

R. FInN and J. Milgram Stanford University Stanford, California 94305

ASSOCIATE EDITORS
R. ARNES
E. F. BeCKenbach
B. H. NeumanN
F. WOLF
K. YoSHIDA

\section{SUPPORTING INSTITUTIONS}

UNIVERSITY OF ARIZONA

UNIVERSITY OF BRITISH COLUMBIA

CALIFORNIA INSTITUTE OF TECHNOLOGY

UNIVERSITY OF CALIFORNIA

MONTANA STATE UNIVERSITY

UNIVERSITY OF NEVADA, RENO

NEW MEXICO STATE UNIVERSITY

OREGON STATE UNIVERSITY
UNIVERSITY OF OREGON

UNIVERSITY OF SOUTHERN CALIFORNIA

STANFORD UNIVERSITY

UNIVERSITY OF HAWAII

UNIVERSITY OF TOKYO

UNIVERSITY OF UTAH

WASHINGTON STATE UNIVERSITY

UNIVERSITY OF WASHINGTON 


\section{Pacific Journal of Mathematics}

\section{Vol. 103, No. $1 \quad$ March, 1982}

Abdul Aziz, On the zeros of composite polynomials ..................

Salomon Benzaquen and Enrique M. Cabaña, The expected measure of the level sets of a regular stationary Gaussian process $\ldots \ldots \ldots \ldots \ldots$

Claudio D’Antoni, Roberto Longo and László Zsidó, A spectral mapping theorem for locally compact groups of operators $\ldots \ldots \ldots \ldots \ldots \ldots \ldots 17$

Ronald Dotzel, Semifree finite group actions on homotopy spheres ........ 25

Daniel H. Gottlieb, The Lefschetz number and Borsuk-Ulam theorems . . . . . 29

Shui-Hung Hou, On property $(Q)$ and other semicontinuity properties of

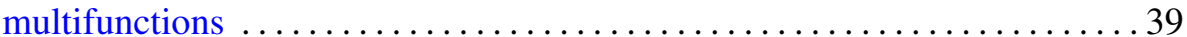

Kevin Mor McCrimmon, Compatible Peirce decompositions of Jordan triple systems

Mitsuru Nakai, Corona problem for Riemann surfaces of Parreau-Widom

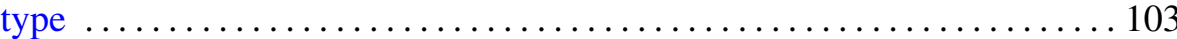

Jack Ray Porter and R. Grant Woods, Extensions of Hausdorff spaces . . . . 111

Milton Rosenberg, Quasi-isometric dilations of operator-valued measures

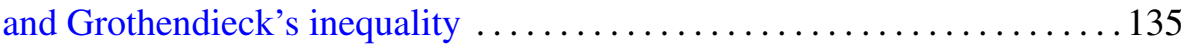

Joseph L. Taylor, A bigger Brauer group $\ldots \ldots \ldots \ldots \ldots \ldots \ldots \ldots \ldots \ldots$

Thomas Vogel, Symmetric unbounded liquid bridges . . . . . . . . . . . 205

Steve Wright, The splitting of operator algebras. II ............... 243 